\title{
Dominantly inherited hyperinsulinism caused by a mutation in the sulfonylurea receptor type 1
}

\author{
Hanna Huopio, ${ }^{1}$ Frank Reimann, ${ }^{2}$ Rebecca Ashfield, ${ }^{2}$ Jorma Komulainen, ${ }^{1}$ \\ Hanna-Liisa Lenko, ${ }^{3}$ Jaques Rahier, ${ }^{4}$ Ilkka Vauhkonen, ${ }^{5}$ Juha Kere, ${ }^{6}$ Markku Laakso, ${ }^{5}$ \\ Frances Ashcroft, ${ }^{2}$ and Timo Otonkoski ${ }^{7}$ \\ ${ }^{1}$ Department of Pediatrics, Kuopio University Hospital, Kuopio, Finland \\ ${ }^{2}$ University Laboratory of Physiology, University of Oxford, Oxford, United Kingdom \\ ${ }^{3}$ Department of Paediatrics, Tampere University Hospital, Tampere, Finland \\ ${ }^{4}$ University Hospital St. Luc, Bruxelles, Belgium \\ ${ }^{5}$ Department of Medicine, Kuopio University Hospital, Kuopio, Finland \\ ${ }^{6}$ Finnish Genome Center, and \\ ${ }^{7}$ Transplantation Laboratory, Haartman Institute, and the Hospital for Children and Adolescents, \\ University of Helsinki, Finland \\ Address correspondence to: Hanna Huopio, Department of Pediatrics, Kuopio University Hospital, PO Box 1777, \\ 70211 Kuopio, Finland. Phone: 358-17-172380; Fax: 358-17-172410; E-mail: Hanna.Huopio@uku.fi.
}

Received for publication March 7, 2000, and accepted in revised form August 28, 2000.

ATP-sensitive potassium channels play a major role in linking metabolic signals to the exocytosis of insulin in the pancreatic $\beta$ cell. These channels consist of two types of protein subunit: the sulfonylurea receptor SUR1 and the inward rectifying potassium channel Kir6.2. Mutations in the genes encoding these proteins are the most common cause of congenital hyperinsulinism (CHI). Since 1973, we have followed up 38 pediatric CHI patients in Finland. We reported previously that a loss-of-function mutation in SUR1 (V187D) is responsible for CHI of the most severe cases. We have now identified a missense mutation, E1506K, within the second nucleotide binding fold of SUR1, found heterozygous in seven related patients with CHI and in their mothers. All patients have a mild form of CHI that usually can be managed by long-term diazoxide treatment. This clinical finding is in agreement with the results of heterologous coexpression studies of recombinant Kir6.2 and SUR1 carrying the E1506K mutation. Mutant $\mathrm{K}_{\mathrm{ATP}}$ channels were insensitive to metabolic inhibition, but a partial response to diazoxide was retained. Five of the six mothers, two of whom suffered from hypoglycemia in infancy, have developed gestational or permanent diabetes. Linkage and haplotype analysis supported a dominant pattern of inheritance in a large pedigree. In conclusion, we describe the first dominantly inherited SUR1 mutation that causes CHI in early life and predisposes to later insulin deficiency.

J. Clin. Invest. 106:897-906 (2000).

\section{Introduction}

Congenital hyperinsulinism (CHI) is a rare genetic disorder characterized by a dysregulation of insulin secretion that leads to severe hypoglycemia. The severity of the disease varies from a mild form, which responds to treatment with drugs (such as diazoxide) or hormones (like somatostatin), to a severe drug-resistant form, which may necessitate resection of the pancreas. Early diagnosis is important to avoid irreversible brain damage due to prolonged hypoglycemia (1-4).

Mutations in four different genes have been associated with CHI (5-10). Most mutations are associated with the $\beta$-cell ATP-sensitive potassium $\left(\mathrm{K}_{\mathrm{ATP}}\right)$ channel, which plays a major role in the regulation of insulin secretion. This channel is open in the unstimulated $\beta$ cell, and its activity keeps the resting membrane potential at a hyperpolarized (negative) level. An increase in the extracellular glucose concentration leads to increased $\beta$-cell metabolism and thus to a rise in the intracellular ATP concentration and a concomitant fall in intracellular ADP. These nucleotide changes act synergistically to close $\mathrm{K}_{\mathrm{ATP}}$ channels, producing depolarization of the $\beta$-cell membrane, activation of voltagegated $\mathrm{Ca}^{2+}$ channels, and finally exocytosis of insulin.

The $\mathrm{K}_{\mathrm{ATP}}$ channel consists of two types of protein subunit: the sulfonylurea receptor SUR1 and the inward rectifying potassium channel Kir6.2 (11). Mutations in the SUR1 gene are the major known cause of CHI (5). However, a few mutations in Kir6.2 have also been found $(6,7)$. In most cases, the disease appears to be diffuse, involving all $\beta$ cells and occurring throughout the pancreas. A focal form has also been described, which is characterized by the somatic loss of maternal alleles and is confined to focal adenomatous lesions of the pancreas (12). All the SUR1 and Kir6.2 mutations described so far have been inherited recessively. However, a gain-of-function mutation in the glucokinase gene (GK) has been 
shown to cause a dominant form of CHI (8). Furthermore, mutations in the glutamate dehydrogenase gene cause CHI with hyperammonemia (9).

The overall incidence of CHI in Finland is 1:40,000, which is about the same as that reported previously for Northern Europe $(13,14)$. The clinical phenotype of Finnish patients with $\mathrm{CHI}$ is variable. We have previously reported a founder mutation, V187D, in the SUR1 gene, which was detected in 15 Finnish patients with $\mathrm{CHI}$. This causes a severe form of $\mathrm{CHI}$ that results from total inactivation of $\beta$-cell $\mathrm{K}_{\mathrm{ATP}}$ channels (13). Efforts are continuing to identify the genetic defects of the remaining patients with $\mathrm{CHI}$ and to correlate the different genotypes and phenotypes. We report here a missense SUR1 mutation that is associated with a mild, diazoxideresponsive form of $\mathrm{CHI}$ and, for the first time to our knowledge, shows a dominant mode of inheritance.

\section{Methods}

Patients. All patients diagnosed with CHI at the Departments of Pediatrics of the five University Central Hospitals of Finland since 1973 were included in this study. These patients are likely to represent all affected individuals diagnosed during that time, but the possibility of single undiagnosed cases cannot be excluded. CHI was diagnosed using generally accepted criteria including nonketotic hypoglycemia, inappropriately elevated insulin levels, and an increased need for glucose administration to prevent hypoglycemia $(1,4)$.

Single-strand conformation polymorphism analysis. Peripheral blood samples were collected from all patients, and DNA was prepared from blood leukocytes by proteinase K-phenol-chloroform extraction. The immediate promoter region of SUR1 (220 bp upstream from the transcriptional start site), all 39 SUR1 exons and flanking introns, the single exon of Kir6.2, the promoter region (334 bp upstream from the transcriptional start site) and 10 exons of glucokinase (GCK) gene, and exons 11 and 12 of glutamate dehydrogenase (GLUD-1) gene were investigated using primers designed by us according to the reported sequences of SUR1 or synthesized as reported previously $(9,15-17)$. The exons were amplified with single-strand conformation polymorphism analysis (PCR-SSCP). The 6- $\mu \mathrm{l}$ reaction mixture consisted of $50 \mathrm{ng}$ of genomic DNA, 5 pmol of each primer, $10 \mathrm{mM}$ Tris- $\mathrm{HCl}$ ( $\mathrm{pH} 8.8), 50$ $\mathrm{mM} \mathrm{KCl}, 1.5 \mathrm{mM}$ of $\mathrm{MgCl}_{2}, 0.1 \%$ Triton X-100, $100 \mu \mathrm{M}$ dNTP, 0.14 units of DNA polymerase (Dynazyme DNA polymerase; Finnzymes, Espoo, Finland) and $0.55 \mu \mathrm{Ci}$ $\alpha-{ }^{33} \mathrm{P}$ dCTP (NEN Life Science Products, Boston, Massachusetts, USA). The PCR conditions were as follows: initial denaturation at $94^{\circ} \mathrm{C}$ for 3 minutes, followed by $30-35$ cycles of denaturation at $94^{\circ} \mathrm{C}$ for $30-60 \mathrm{sec}-$ onds; annealing at $58-65^{\circ} \mathrm{C}$ for $30-60$ seconds, and extension at $72^{\circ} \mathrm{C}$ for $30-60$ seconds; and a final extension at $72^{\circ} \mathrm{C}$ for 6 minutes.

SSCP was performed essentially according to the method of Orita et al. (18). The PCR products were first diluted two- to 20 -fold with $0.1 \%$ SDS and $10 \mathrm{mM}$
EDTA and were then diluted (1:1) with loading mix (95\% formamide, $20 \mathrm{mM}$ EDTA, 0.05\% bromphenol blue, and $0.05 \%$ xylene cyanol). After denaturation at $98^{\circ} \mathrm{C}$ for 3 minutes, samples were immediately cooled on ice. A total of $3 \mu \mathrm{l}$ of each sample was loaded onto a $5 \%$ (PCR products > $230 \mathrm{bp}$ ) or a 6\% (PCR products < $230 \mathrm{bp}$ ) nondenaturing polyacrylamide gel (acrylamide/ $N, N$-methylene-bis-acrylamide ratio 49:1) containing $10 \%$ of glycerol. The runs were performed at two different gel temperatures: $38^{\circ} \mathrm{C}$ for approximately 4 hours and $29^{\circ} \mathrm{C}$ for 5 hours. Autoradiography was carried out overnight at $-70^{\circ} \mathrm{C}$ with intensifying screens.

Direct sequencing. Variant forms of DNA detected by SSCP analysis were identified by direct sequencing (Thermo Sequenase Radiolabeled Terminator Cycle Sequencing Kit; USB Corp., Cleveland, Ohio, USA) and verified by restriction fragment length polymorphism analysis (RFLP) on a $3 \%$ agarose gel (NuSieve GTG; FMC Bioproducts, Rockland, Maine, USA).

Detection of mutation E1506K. To detect the mutation E1506K, PCR amplification of genomic DNA was performed using the primers $5^{\prime}$-ATCCCATCTGCTCCACTCAC-3' and 5'-ATCCCACTAAACCCTTTCCAG-3'. After sequencing the SSCP variant, the mutant sequence was confirmed by digestion of the 253-bp product with the restriction enzyme MnlI (New England Biolabs Inc., Beverly, Massachusetts, USA). The PCR-product amplified from $50 \mathrm{ng}$ of genomic DNA was digested with 2 $\mathrm{U}$ of the enzyme for 16 hours at $37^{\circ} \mathrm{C}$ and separated by electrophoresis in 9\% PAGE. The wild-type sequence results in 105-bp, 61-bp, 33-bp, 29-bp, and 28-bp products. The mutation E1506K causes a disappearance of one of the restriction sites of MnlI and leads to the formation of a new 89-bp product

Haplotype analysis. Three microsatellite markers D11S1890, D11S921, and D11S1888 were chosen for haplotype analysis. Both SUR1 and Kir6.2 genes map between the markers D11S1890 and D11S1888 and on either side of the marker D11S921. One of the primers was labeled with fluorescein during synthesis. The polymorphic DNA fragments were amplified by PCR using optimized conditions. Electrophoresis was carried out to separate dinucleotide alleles of different sizes, using an automatic laser fluorescence DNA sequencer (ALFexpress; Pharmacia Biotech A/B, Uppsala, Sweden) with 6\% Hydrolink gels. Two internal standards were included in each line.

Linkage analysis. Two-point linkage analysis was calculated using the LINKAGE package (19).

Histological studies. The resected pancreas of case 1 and pancreases from normoglycemic controls were fixed in formalin and embedded in paraffin. Five-micrometer sections were processed for hematoxylin-eosin and for anti-insulin, anti-somatostatin, and anti-glucagon immunoperoxidase staining as described previously (20). The volume densities of the cell populations were measured by the point-counting method (20). The mean nuclear radius of the largest $\beta$-cell nuclei per $1,000 \mu \mathrm{m}^{2}$ of $\beta$-cell cytoplasm were measured using a 
semiautomatic image analyzer (Videoplan Kontron, Munich, Germany) as described previously (21).

Studies of glucose metabolism. Detailed studies of glucose metabolism were performed on the mothers of cases 1 and 4 . On the first day, the degree of glucose tolerance was evaluated by an 2-hour oral glucose tolerance test (OGTT) (75 g glucose). Immediately after the OGTT, a hyperglycemic clamp was performed to evaluate the maximal glucose stimulated insulin and C-peptide secretory capacity (22). Blood glucose was acutely increased to $20 \mathrm{mM}$ by a constant glucose infusion and clamped at $20 \mathrm{mM}$ for 1 hour by infusing $20 \%$ glucose at varying rates, determined by blood glucose measurements performed at 5-minute intervals. At 150, 165, and 180 minutes, samples were taken for the measurement of plasma insulin and C-peptide. The mean values of samples drawn at 150,165 , and 180 minutes were used when evaluating the insulin secretion capacity.

On the second day, the first-phase insulin secretory capacity was determined by an intravenous glucose tolerance test (IVGTT). After a 12-hour overnight fast, a bolus of glucose $(300 \mathrm{mg} / \mathrm{kg}$ in $50 \%$ solution) was infused into antecubital vein to increase the blood glucose level acutely. Blood glucose and plasma insulin samples were collected at $-5,0,2,4,6,8$, and 10 minutes. The insulin response was evaluated by the area under the curve, which was calculated by trapezoidal method. The degree of insulin resistance was evaluated with the euglycemic hyperinsulinemic clamp technique. After an IVGTT, a priming dose of insulin (Actrapid $100 \mathrm{IU} / \mathrm{ml}$; Novo Nordisk, Gentofte, Denmark) was infused for 10 minutes to raise the plasma insulin rapidly to the desired level, at which it was maintained by continuous insulin infusion at a rate of $120 \mathrm{mU} / \mathrm{m}^{2}$ body surface area per minute. Blood glucose was clamped at $5.0 \mathrm{mM}$ for the next 120 minutes by infusing $20 \%$ glucose at varying rates, according to blood glucose measurements performed at 5-minute intervals. The data were calculated for each 20-minute interval; the mean value for the period from 60 to 120 minutes was used to calculate the rates of whole-body glucose uptake (M-value).

\section{Recombinant $\mathrm{K}_{A T P}$ channel studies}

Construction of CHI-SUR1. Site-directed mutagenesis of rat SUR1 (GenBank no. L40624) was carried out by subcloning the appropriate fragments into the pALTER vector, and mutagenesis was carried out according to the Promega Altered Sites II in vitro Mutagenesis Systems protocol (Promega Corp., Madison, Wisconsin, USA). Synthesis of capped mRNA was carried out using the mMessage mMachine in vitro transcription kit (Ambion, Austin, Texas, USA). Wild-type or mutant SUR1 was coexpressed with mouse Kir6.2 (GenBank D50581) (23, 24).

Electrophysiology. Female Xenopus laevis were anesthetized with MS222 (2 g/l added to the water). One ovary was removed via a mini-laparotomy, the incision sutured, and the animal allowed to recover. Once the wound had completely healed, the second ovary was removed in a similar operation, and the animal was then sacrificed by decapitation while under anesthesia. Immature stage V-VI Xenopus oocytes were manually defolliculated, and oocytes were co-injected with approximately $0.1 \mathrm{ng}$ Kir6.2 and approximately 2 ng of SUR (wild type or mutant), giving a 1:20 ratio. The final injection volume was approximately $50 \mathrm{nl} /$ oocyte. Control oocytes were injected with water. Isolated oocytes were maintained in Barth's solution and studied 1-4 days after injection (25).

Two-electrode voltage clamp studies. Whole-cell currents were recorded from intact oocytes using a two-electrode voltage-clamp (Geneclamp 500; Axon Instruments Inc., Foster City, California, USA), filtered at $1 \mathrm{kHz}$ and digitized at $4 \mathrm{kHz}(25)$. Whole-cell currents were measured 280-295 milliseconds after the start of the voltage pulse. Oocytes were constantly perfused with a solution containing $90 \mathrm{mM} \mathrm{KCl}, 1 \mathrm{mM} \mathrm{MgCl}, 1.8 \mathrm{mM} \mathrm{CaCl}_{2}$, and 5 mM HEPES ( $\mathrm{pH} 7.4$ with $\mathrm{KOH}$ ). Metabolic inhibition was produced by perfusion with $3 \mathrm{mM} \mathrm{Na}$-azide.

Excised patch studies. Patch pipettes were pulled from thick-walled glass and had resistances of $250-500 \mathrm{k} \Omega$ when filled with pipette solution. Macroscopic currents were recorded from giant inside-out patches using an EPC7 patch-clamp amplifier (List Electronik, Darmstadt, Germany) at $20-24^{\circ} \mathrm{C}(25)$. The holding potential was $0 \mathrm{mV}$, and currents were evoked by repetitive 3 second voltage ramps from -110 to $+100 \mathrm{mV}$. Currents were filtered at $0.2 \mathrm{kHz}$, digitized at $0.5 \mathrm{kHz}$ using a Digidata 1200 Interface, and analyzed using pClamp software (Axon Instruments Inc.). The pipette solution contained $140 \mathrm{mM} \mathrm{KCl}, 1.2 \mathrm{mM} \mathrm{MgCl}_{2}, 2.6 \mathrm{mM} \mathrm{CaCl}_{2}$, $10 \mathrm{mM}$ HEPES ( $\mathrm{pH} 7.4$ with $\mathrm{KOH}$ ), and the internal (bath) solution contained $110 \mathrm{mM} \mathrm{KCl}, 2 \mathrm{mM} \mathrm{MgCl}$, $1 \mathrm{mM} \mathrm{CaCl}_{2}, 30 \mathrm{mM} \mathrm{KOH}, 10 \mathrm{mM}$ EGTA, $10 \mathrm{mM}$ HEPES ( $\mathrm{pH} 7.2$ with $\mathrm{KOH}$ ), and nucleotides as indicated. Solutions containing ATP were made up fresh each day, and the $\mathrm{pH}$ was readjusted after addition of ATP. Diazoxide was prepared as a $200 \times$ stock solution in 0.1 $\mathrm{M} \mathrm{KOH}$, and tolbutamide as a $100 \mathrm{mM}$ stock solution in $0.15 \mathrm{M} \mathrm{KOH}$. Rapid exchange of solutions was achieved by positioning the patch in the mouth of one of a series of adjacent inflow pipes placed in the bath.

The slope conductance was measured by fitting a straight line to the current-voltage relation between -20 and $-100 \mathrm{mV}$ : the average of five consecutive ramps was calculated in each solution. ATP dose-response relationships were measured by alternating test and control solutions. Conductance was expressed as a fraction of the mean of that obtained in control solution before and after ATP application. ATP dose-response curves were fit to the Hill equation: $G / G_{c}=1 /(1+$ $\left.\left([\mathrm{ATP}] / \mathrm{K}_{\mathrm{i}}\right)^{\mathrm{h}}\right)$, where $[\mathrm{ATP}]$ is the ATP concentration, $K_{i}$ is the ATP concentration at which inhibition is half maximal, and $b$ is the slope factor (Hill coefficient).

All data are given as mean $\pm \mathrm{SEM}$. The symbols in the figures indicate the mean, and the vertical bars indicate 1 SEM (where this is larger than the symbol). Statistical significance was tested by Student's $t$ test or ANOVA, as appropriate. 

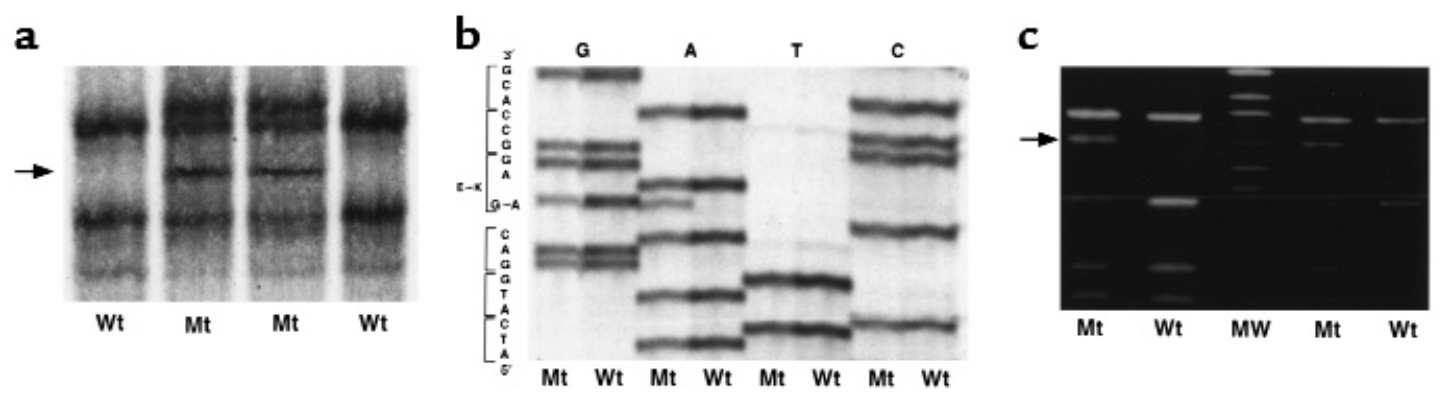

\section{Figure 1}

Demonstration of the mutation E1506K. (a) SSCP-analysis of the SUR1 exon 37. Results are shown for two individuals carrying the E1506K mutation (Mt) and two controls $(\mathrm{Wt})$. The abnormally migrating DNA fragment is marked with an arrow. The gel was run for 4 hours at $38^{\circ} \mathrm{C}$. (b) Sequence analysis reveals a $G \rightarrow A$ mutation in the genomic sequence resulting in the substitution of glutamic acid for lysine. (c) Detection of the mutation by restriction analysis of PCR-amplified genomic DNA. Mutation E1506K causes the disappearance of a Mnll restriction site, leading to the formation of a new 89-bp digestion product for the mutated allele (arrow). MW, molecular weight marker; Mt, mutant; Wt, wild type.

\section{Results}

Detection of the mutation E1506K. The PCR-SSCP analysis revealed abnormally migrating DNA fragments in seven of the 38 patient samples in exon 37 of SUR1 (Figure 1a). Sequencing of the variant (case 1) led to the detection of a heterozygous $\mathrm{GAG} \rightarrow$ AAG substitution in codon 1506, resulting in an amino acid change from glutamic acid to lysine (E1506K) (Figure 1b). This mutation is located in the second nucleotide binding fold of the SUR1 protein.

The presence of this missense mutation results in the disappearance of a $\mathrm{MnlI}$ restriction endonuclease site and the formation of a new 89-product that provides a means to confirm and test for its presence (Figure 1c). In all seven cases, the individuals were heterozygous for the mutation and the mutation was maternally inherited. No other mutations in the SUR1, Kir6.2, glucokinase (GCK), or exon 11 and 12 of the glutamate dehydrogenase (GLUD1) genes were found in any of these individuals. The E1506K mutation was not found in 100 normal Finnish chromosomes. We also examined 160 chromosomes of type 2 diabetic patients, and the mutation was not detected in any of them.

Genetic linkage analysis. The large six-generation pedigree with six patients was analyzed for genetic linkage using both nonparametric and parametric approaches. We first tested for the significance of the observation that a haplotype including a rare single nucleotide polymorphism, E1506K, was inherited by all of the affected individuals but by none of those unaffected in the previous generation. This calculation makes no assumptions about the mode of inheritance. The shared haplotype was assumed to be introduced in the pedigree only once in any of the four chromosomes possessed by the founding couple. The likelihood of obtaining the observed haplotype-sharing pattern by chance was $1.2 \times 10^{-7}$, strongly supporting the hypothesis that the segregation of CHI in the pedigree was dependent on the segregation of the haplotype.

We then performed two-point linkage analysis with dominant and recessive models of inheritance. All but the last generation of individuals were considered as of unknown phenotype, whereas for the last generation, unaffected and affected individuals were as marked in Figure 2. The linkage of the mutant allele to the phenotype was calculated using a dominant model that assumes an allele frequency of 0.01 , full penetrance, and no phenocopies. A maximum LOD score of 6.28 was obtained for $\theta=0$. A recessive model yielded a maximum LOD score of 4.10 at $\theta=0.044$, and thus fits the data less well. Using an allele frequency of 0.03 , corresponding to the frequency of the conserved haplotype, the figures were $\operatorname{LOD} 6.00$ at $\theta=0$ and LOD 3.83 at $\theta=0.045$ for the dominant and recessive models, respectively.

Table 1

Major clinical findings of $\mathrm{CHI}$ patients carrying the mutation E1506K

\begin{tabular}{lccccccc}
\hline Patient & Sex & Age (yrs) & $\begin{array}{c}\text { Gestational age } \\
(\text { wks })\end{array}$ & $\begin{array}{c}\text { Birth weight } \\
(\mathrm{g} ; \mathrm{SD})\end{array}$ & $\begin{array}{c}\text { Blood glucose }(\mathrm{mM}) ; \\
\text { plasma insulin }(\mathrm{mU} / \mathrm{l}))^{\mathrm{A}}\end{array}$ & $\begin{array}{c}\text { Diazoxide } \\
\text { treatment }\end{array}$ & $\begin{array}{c}\text { Pancreatectomy } \\
+\end{array}$ \\
\hline & Male & 26 & 34 & 3,$830 ;+4.2$ & & - & - \\
2 & Female & 18 & 36 & 3,$500 ;+1.6$ & $2.2 ; 22$ & - & - \\
3 & Female & 15 & 39 & 4,$440 ;+2.0$ & $2.0 ; 26$ & + \\
4 & Female & 15 & 38 & 4,$500 ;+2.9$ & $1.4 ; 24$ & + \\
5 & Female & 8 & 37 & 5,$360 ;+5.5$ & $2.4 ; 164$ & + \\
6 & Female & 5 & 38 & 4,$330 ;+2.5$ & $1.5 ; 23$ & + \\
7 & Male & 3 & 36 & 3,$150 ;+0.4$ & $1.2 ; 31$ & + \\
\hline
\end{tabular}

ARecordings given for blood glucose and plasma insulin are those resulting in the highest ratio of simultaneous insulin and glucose values. 
Clinical findings. The clinical characteristics of the seven pediatric patients who carry the mutation E1506K are presented in Table 1. Five of the patients were large for their gestational age. Five patients presented with hypoglycemia during the first few hours after birth. In the other two cases, the symptoms of hypoglycemia appeared later, at the age of 5 (case 4) and 7 (case 2) months. Hyperinsulinemia during hypoglycemia was used as the major diagnostic criterion for CHI. In case 1, the level of hyperinsulinemia was not documented.

Five patients were treated with diazoxide, and four of them showed a good response (cases 4-7). In case 1, subtotal pancreatectomy was performed at the age of 3.5 years in preference to diazoxide treatment. In one case, the duration of the diazoxide treatment was 5 years (case 4), and the remaining three are still on medication. In the two mildest cases $(2,3)$, hypoglycemia was treated with extra glucose administration and frequent feeds without the need for medication.

Histological examination was possible only in case 1, who underwent a subtotal pancreatectomy. The resected pancreas was macroscopically unremarkable. After hematoxylin-eosin staining, the histological features were similar in the different parts of the gland: the islets, although slightly irregular in contour, appeared roughly normal, and their number was not increased. In most islets, abnormally large nuclei were observed, corresponding to $\beta$ cells with an abundant cytoplasm (Figure 3a).

Immunoperoxidase after antiinsulin antibody stained not only insular but also extrainsular $\beta$ cells that appeared either in small clusters or scattered within the exocrine tissue (Figure 3b). The labeling intensity of the insulin-containing cells was similar in the different regions of the gland. The distribution of non- $\beta$ cells also appeared to be normal. The volume density of endocrine tissue measured by point-counting studies of immunostained sections was $1.95 \%$ in the $\mathrm{CHI}$ pancreas compared with $3.2 \%$ in control pancreas; The proportions of $\beta, \delta$, and $\alpha$ cells were, respectively, $54 \%, 22 \%$, and $19 \%$ versus $53 \%, 26 \%$, and $19 \%$ in normoglycemic controls. The mean radius of 50 selected $\beta$-cell nuclei was high compared with the controls (4.61 vs. $3.19 \mu \mathrm{m}$ ), and the index of $\beta$-cell nuclear crowding was low (9.94 nuclei per 1,000 $\mu \mathrm{m}^{2}$ of $\beta$-cell cytoplasm versus 13.78 nuclei in the controls).
It was possible to extract DNA from three paraffinembedded tissue blocks originating from different parts of the pancreas. The DNA was partially degraded, probably because the pancreas was resected 23 years earlier. Nevertheless, the primers of the marker D11S1890 amplified a product showing two different alleles $(3,4)$, which were the same as in the genomic DNA, from all three parts of the pancreas, thus excluding the possibility of somatic loss of heterozygosity in these areas of the pancreas.

At least two of the mothers (cases 1 and 5; generation II), who are sisters, had had symptoms that could be classified as hypoglycemic, during the first 2 years of life. These symptoms always manifested early in the morning and included irritability, convulsions, deviation of the eyes, and even unconsciousness. Unfortunately, no documentation of blood glucose values is available. Their brother had been lethargic and floppy soon after birth, and he died at the age of 2 days. The grandmother of cases 1, 4, and 5 in generation III, and the mothers of cases 4,6 , and 7 , had had mild symptoms of hypoglycemia, including trembling and sweating, during fasting. The brother of this grandmother in generation III died at the age of 2 days from unknown causes. The fathers of the seven patients were unrelated, and none of them carried the mutation. The haplotypes inherited paternally were all very different (Figure 2).

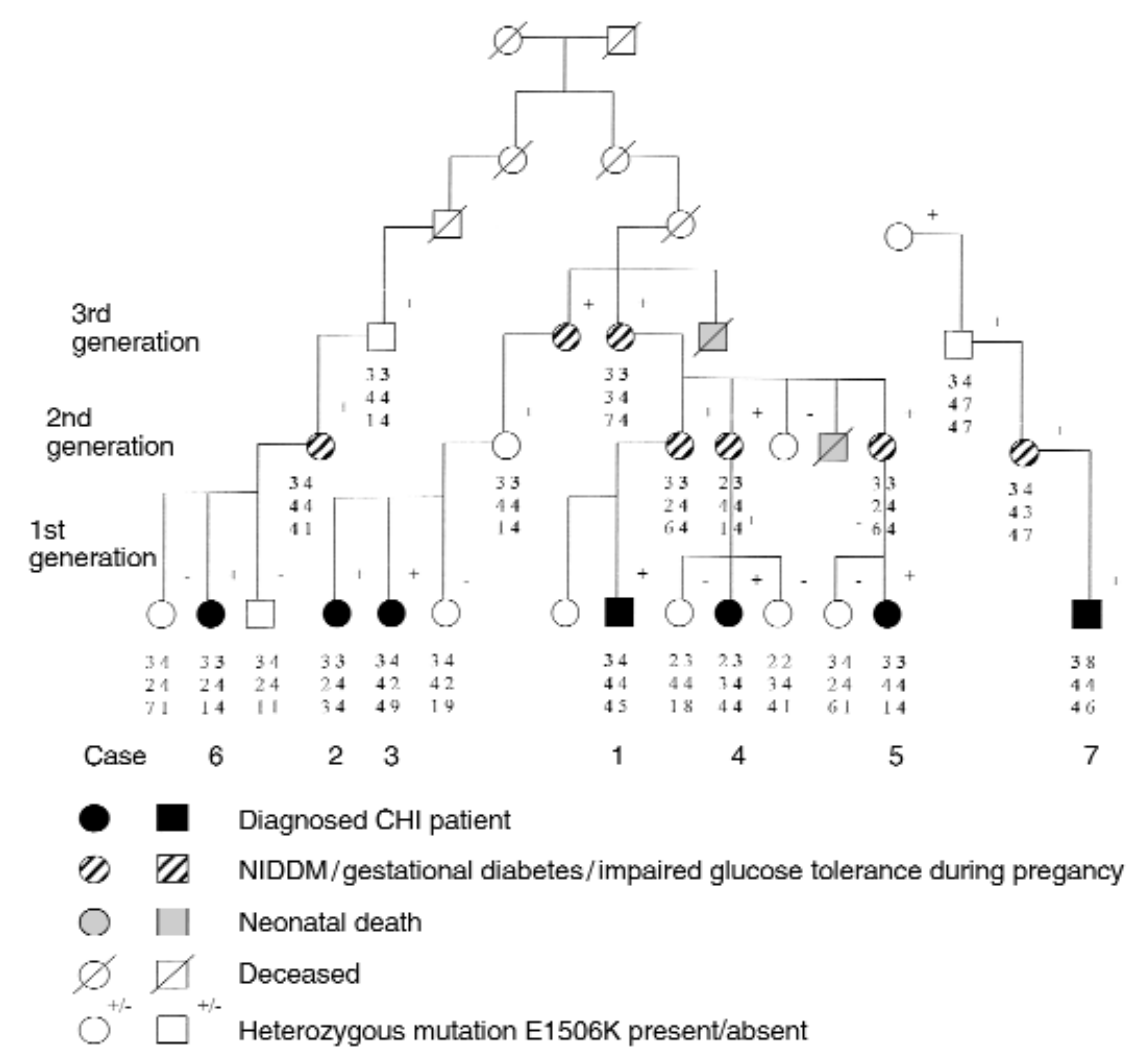

Figure 2

Pedigree and haplotype analysis of a large pedigree carrying the SUR1 mutation E1506K. The order of markers of the haplotype is as follows: D11S1890, D11S921, D11S1888. The haplotypes are presented below each individual. The haplotype 3-4-4 associates with E1506K in all cases. 

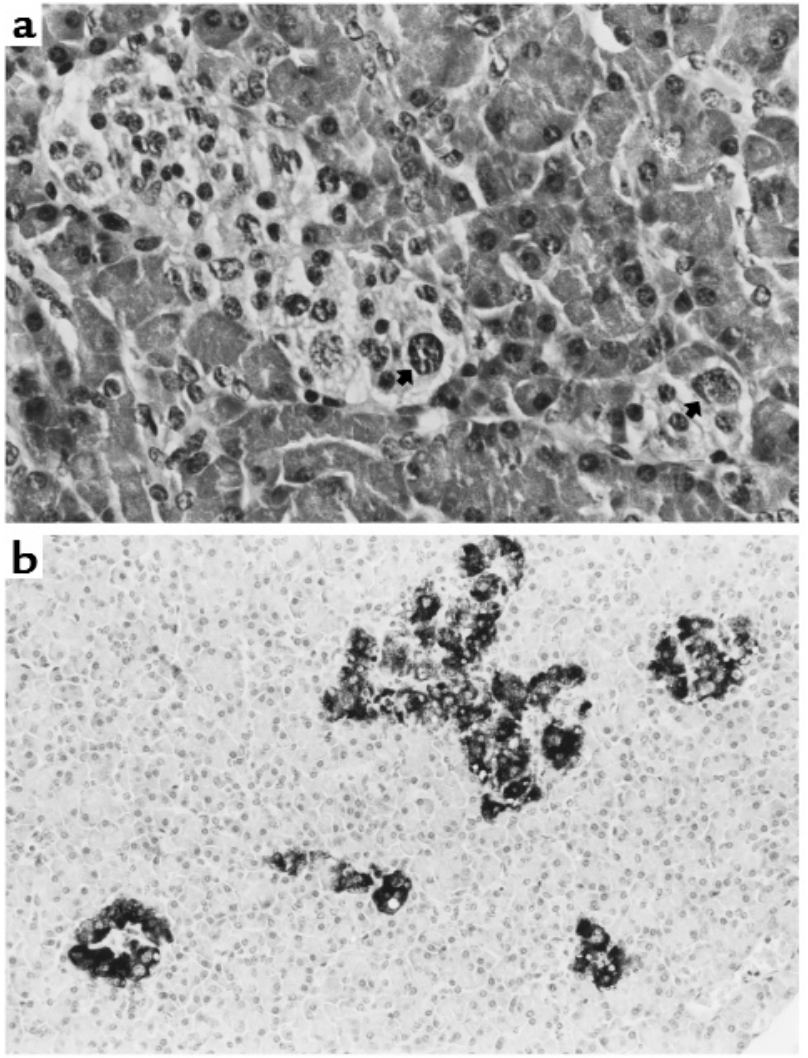

Figure 3

Pancreatic histology of case 1. (a) Hematoxylin-eosin-stained section showing abnormal $\beta$ cell nuclei (arrows). Objective magnification $\times 40$. (b) Immunoperoxidase staining of insulin reveals irregular islets and small clusters of $\beta$ cells. Objective magnification $\times 10$.

All except one of the mothers (the mother of cases 2 and 3 , generation II) had impaired glucose tolerance or diabetes during pregnancy. One of them was treated with insulin, and four had pathological values in the OGTT. Two of them have developed diabetes. Furthermore, the grandmother of the affected children (cases 1, 4, and 5) is diabetic. All of these diabetic persons have a tendency to hypoglycemia when treated with sulfonylureas.

To evaluate the $\beta$-cell sensitivity to glucose and the tissue sensitivity to insulin, the glucose metabolism of two diabetic mothers was investigated in detail. The results of the studies are shown in Table 2. OGTT values showed diabetic levels according to the World Health Organization criteria (26) in both cases. Both the first-phase and the maximal glucose-stimulated insulin secretory capacity were severely reduced. The Mvalues during the euglycemic clamp were relatively high compared with those of type 2 diabetic patients evaluated previously in our laboratory.

Recombinant $K_{A T P}$ channel experiments. We first compared the effect of metabolic inhibition on oocytes coinjected with Kir6.2 and either SUR1 or SUR1-E1506K. Intact oocytes were voltage-clamped using two electrodes, and $3 \mathrm{mM}$ azide was used as a metabolic poison.
As shown in Figure 4, oocytes exhibited very small current amplitudes in control solution. Metabolic poisoning induced a large increase in Kir6.2/SUR1-injected oocytes but had little effect on the currents recorded from oocytes injected with Kir6.2/SUR1-E1506K. Subsequent addition of diazoxide in the continued presence of azide, however, activated both Kir6.2/SUR1 and Kir6.2/SUR1-E1506K currents. These currents were blocked by $500 \mu \mathrm{M}$ tolbutamide, indicating that they flowed through $\mathrm{K}_{\mathrm{ATP}}$ channels.

These results suggest that SUR1-E1506K is capable of forming functional channels with Kir6.2, and that these channels are insensitive to metabolic inhibition but can be opened by diazoxide. This result is consistent with the ability of diazoxide, but not low blood glucose, to inhibit insulin secretion in patients with CHI who were carrying the SUR1-E1506K mutation.

Figure 5a compares the macroscopic currents recorded before and after patch excision from oocytes coexpressing Kir6.2 and either SUR1 or SUR1-E1506K. In all cases, currents recorded in the cell-attached condition were extremely small $(<50 \mathrm{pA})$, consistent with the results obtained for intact oocytes in control solution. After excision into nucleotide-free intracellular solution, patches excised from oocytes expressing wild-type Kir6.2/SUR1 developed very large currents; this increase in current on patch excision reflects the relief of channel inhibition by ATP present in the oocyte cytoplasm. Smaller, but still substantial, Kir6.2/SUR1E1506K currents were also observed in excised patches.

We next explored the functional properties of Kir6.2/SUR1-E1506K channels. There was no significant difference in the ATP-sensitivity of Kir6.2/SUR1-E1506K (Figure $5 \mathrm{~b}$ ) and wild-type $\mathrm{K}_{\mathrm{ATP}}$ channels. The mean $\mathrm{IC}_{50}$ for ATP inhibition of Kir6.2/SUR1-E1506K currents was

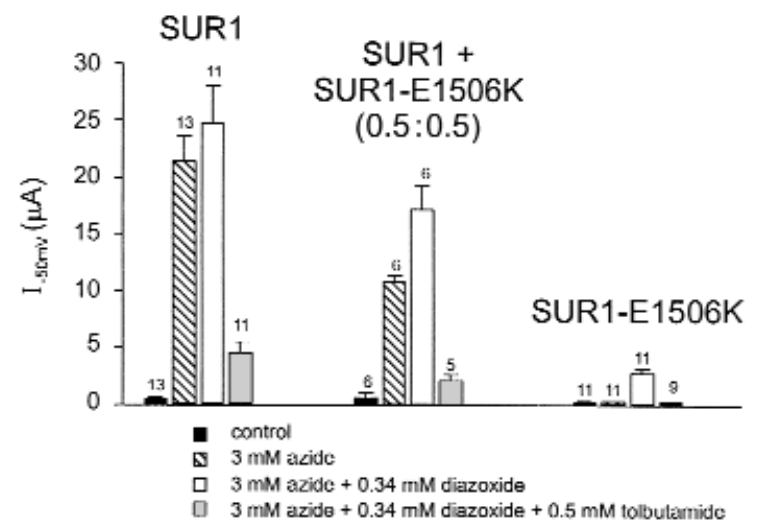

\section{Figure 4}

Effects of metabolic inhibition on wild-type and mutant Kir6.2/SUR1 currents. Mean whole-cell current amplitudes recorded at $-50 \mathrm{mV}$ first in control solution (black bars), 15 minutes after exposure to 3 $\mathrm{mM}$ azide (hatched bars), then in the continued presence of azide plus $340 \mu \mathrm{M}$ diazoxide (white bars), and, finally, after the further addition of $500 \mu \mathrm{M}$ tolbutamide (shaded bars). Oocytes were coinjected with mRNA encoding Kir6.2 and either SUR1, SUR1E1506K, or a 1:1 mixture of SUR1 plus SUR1-E1506K, as indicated. The number of oocytes is given above the error bars. 
Table 2

Studies of glucose metabolism in individuals carrying the E1506K mutation (mothers of cases 1 and 4$)^{A}$

Mother of case 1

Mother of case 4

Control $($ mean \pm SD)

OGTT

Fasting blood glucose $(\mathrm{mM})$

Blood glucose at 2 hours (mM)

IVGTT

AUCIVI ( $\mathrm{mU} / \mathrm{I} \min )$

Hyperglycemic clamp

P-insulin ( $\mathrm{mU} / \mathrm{l})$

C-peptide (nM)

Euglycemic clamp

M-value $(\mathrm{mg} / \mathrm{kg} / \mathrm{min})$

$\begin{array}{ccc}9.5 & 6.2 & \\ 16.5 & 12.3 & \\ & & \\ 6.1 & 19.6 & 143 \pm 372^{\mathrm{B}} \\ & & 3.85 \pm 0.95^{\mathrm{B}} \\ 19.0 & 24.3 & \\ 1.2 & 1.5 & 4.45 \pm 1.78 / 10.9 \pm 3.1^{\mathrm{C}} \\ 9.36 & 7.19 & \end{array}$

AThe insulin response during the IVGTT evaluated by the area under the curve; the maximal P-insulin and C-peptide secretion during the hyperglycemic clamp; the whole-body glucose uptake (M-value). ${ }^{B}$ Results of 19 healthy control subjects without a family history of diabetes examined in our laboratory using the same method (40). CResults of nine diabetic patients with insulin resistance versus 19 healthy controls examined in our laboratory using the same glucose clamp methods $\left(120 \mathrm{mU} / \mathrm{m}^{2}\right)$. oocytes were co-injected with Kir6.2, and the same total concentration of either wild-type or mutant SUR1. Figure 4 shows that the amplitude of $\mathrm{K}_{\mathrm{ATP}}$ current activated by metabolic inhibition in oocytes expressing Kir6.2 and a 1:1 mixture of wild-type and mutant SUR1 was approximately half that found for oocytes expressing Kir6.2/SUR1 channels. Because the concentration of SUR 1 mRNA in the mRNA mixture was also approximately $50 \%$ of that in oocytes injected with SUR1 alone, this result indicates that the E1506K mutation does not have a dominant negative effect.
$9.3 \pm 1.1 \mu \mathrm{M}(n=4)$, similar to that measured previously for Kir6.2/SUR1 currents $(21 \mu \mathrm{M} ; 12 \mu \mathrm{M})(27,28)$. The Hill coefficient was close to unity $(b=0.96 \pm 0.1 ; n=4)$, as found before for Kir6.2/SUR1. The values of $\mathrm{IC}_{50}$ and $b$ we observed are also similar to those found for native $\beta$ cell $\mathrm{K}_{\text {ATP }}$ channels $(29,30)$. Thus, these data indicate that the failure of Kir6.2/SUR1-E1506K channels to respond to metabolic inhibition is not a consequence of an altered ATP sensitivity.

We next examined the effect of MgADP on Kir6.2/SUR1-E1506K channel activity. As shown in Figure 6, a(ii) and b, $100 \mu \mathrm{M}$ MgADP blocked the channel by approximately $70 \%$. This contrasts with wildtype $\mathrm{K}_{\mathrm{ATP}}$ channels, where MgADP stimulates channel activity by approximately $170 \%$ (Figure $6 \mathrm{~b}$ ). The lack of MgADP activation may contribute to the failure of metabolic inhibition to stimulate Kir6.2/SUR1E1506K currents in intact oocytes.

The K-channel opener diazoxide is able to reverse, almost completely, the inhibitory effect of $100 \mu \mathrm{M}$ ATP on wild-type Kir6.2/SUR1 channels (Figure 6b). Diazoxide was far less effective on Kir6.2/SUR1-E1506K channels, although it did increase channel activity to a small extent (Figure 6, a[iii] and b). This can be seen more clearly when the conductance recorded in the presence of ATP and diazoxide is expressed as a percentage of that recorded in ATP alone (Figure 6b, inset). Although the response to diazoxide was small, it is worth emphasizing that because of the very high input resistance of the $\beta$ cell when the $K_{A T P}$ channels are closed, even a very small current is capable of producing a large hyperpolarization and thereby inhibiting insulin secretion. The sulfonylurea tolbutamide blocked both wild-type and Kir6.2/SUR1-E1506K currents by a similar amount (Figure 6, a[i] and b).

Unlike most CHI mutations, heterozygosity for E1506K is sufficient to cause the disease. To determine whether this arises from a gene dosage or a dominant negative effect, we examined the effect of coexpressing Kir6.2 with a 1:1 mixture of wild-type and mutant SUR1. Control

\section{Discussion}

In most cases, $\mathrm{CHI}$ is caused by a recessive mutation in the SUR1 gene. The other genes that can cause a similar phenotype include Kir6.2, glucokinase, and glutamate dehydrogenase. Our linkage analyses show unambiguously that $\mathrm{CHI}$ in the patients described here depends on the inheritance of the E1506K allele of the SUR1 gene. Nonparametric analysis showed that the
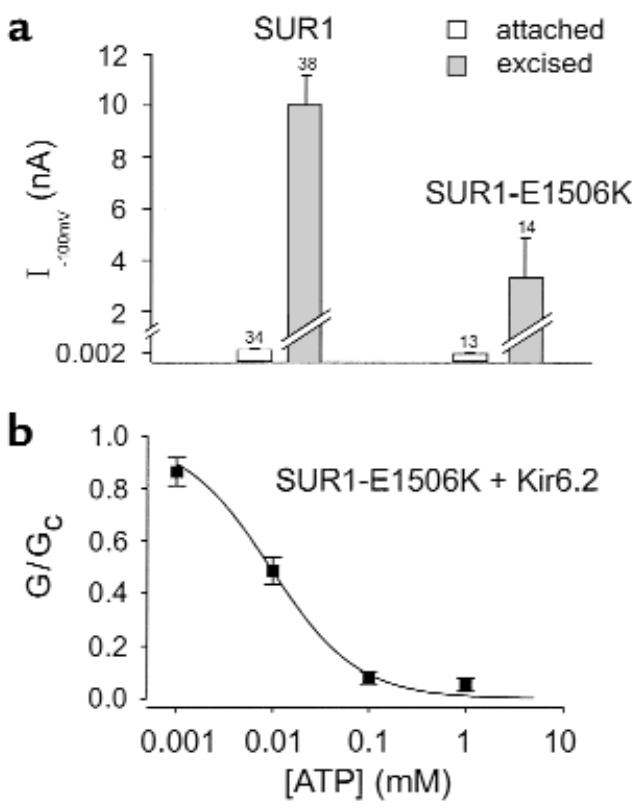

Figure 5

(a) Current amplitudes recorded in excised patches. Mean current amplitudes recorded at $-100 \mathrm{mV}$ in the cell-attached or inside-out patch configuration from oocytes co-injected with Kir6.2 and either SUR1 or SUR-E1506K as indicated. The number of oocytes is given above the bars. (b) ATP sensitivity of Kir6.2/SUR1-E1506K currents; mean ATP concentration-response relationships for Kir6.2/SUR1E1506K currents $(n=4)$. The slope conductance $(G)$ is expressed as a fraction of the mean $\left(G_{c}\right)$ of that obtained in control solution before and after the exposure to ATP: The line is the best fit of the data to Hill equation $\left(\mathrm{IC}_{50}=9.3 \mu \mathrm{M}\right.$ and $\left.h=0.96\right)$. 
a
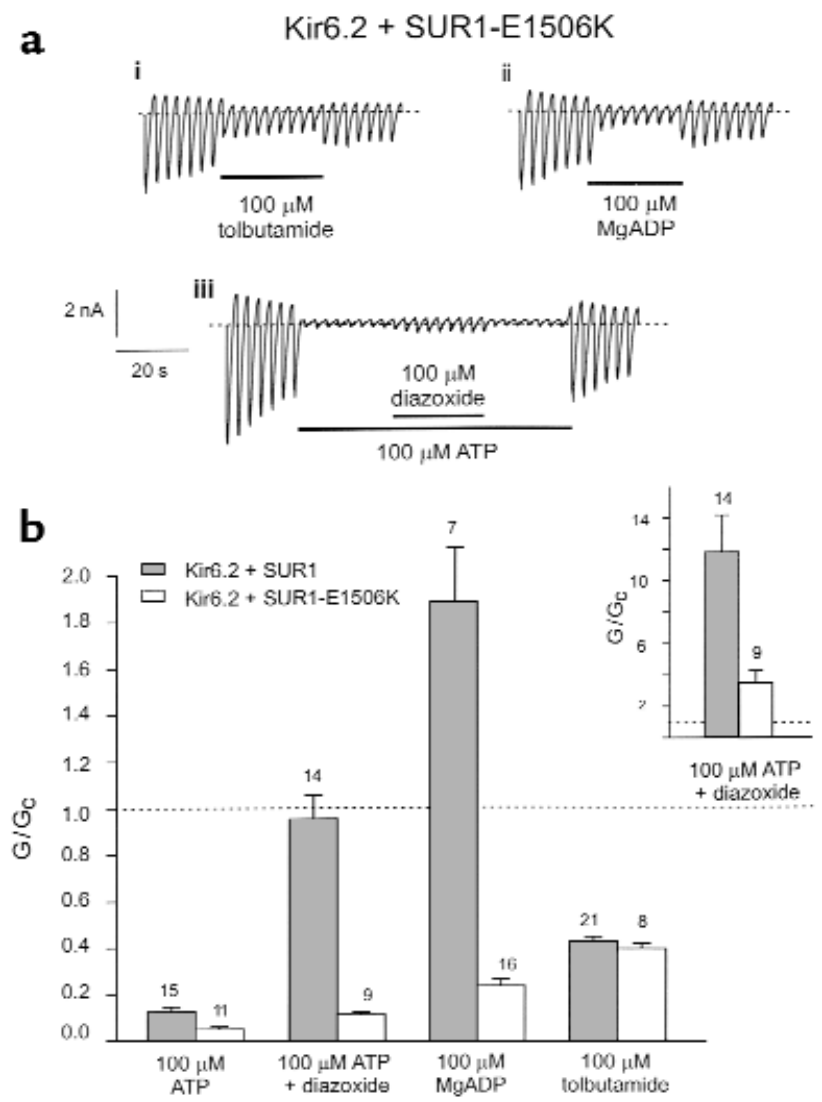

Figure 6

Effects of MgADP, tolbutamide, and diazoxide on Kir6.2/SUR1E1506K currents. (a) Macroscopic Kir6.2/SUR1-E1506K currents recorded from inside-out patches in response to series of voltage ramps from $-110 \mathrm{mV}$ to $+100 \mathrm{mV}$. Tolbutamide $(100 \mu \mathrm{M})$, ADP $(100$ $\mu \mathrm{M})$, diazoxide $(340 \mu \mathrm{M})$, and ATP $(100 \mu \mathrm{M})$ were added to the internal solution as indicated by the bars. (b) Mean macroscopic slope conductance recorded in the presence of ATP, ATP plus diazoxide, ADP, or tolbutamide, expressed as percentage of the slope conductance in control solution. The number of oocytes is given above the bars. Inset: Mean macroscopic slope conductance recorded in the presence of $100 \mu \mathrm{M}$ ATP plus $340 \mu \mathrm{M}$ diazoxide, expressed as a percentage of the current in the presence of $100 \mu \mathrm{M}$ ATP for Kir6.2/SUR and Kir6.2/SUR1-E1506K currents. The dashed line indicates the conductance in the presence of $100 \mu \mathrm{M}$ ATP. The number of oocytes is given above the bars.

observed sharing among patients and nonsharing among healthy sibs in the large pedigree is highly unlikely to be caused by chance $\left(P=1.2 \times 10^{-7}\right)$. Parametric linkage analysis, surprisingly, strongly supported a dominant mode rather than rather than a recessive mode of inheritance.

A dominant rather than a recessive mechanism is also suggested by the inspection of the haplotypes surrounding the SUR1 gene in the patients. For all patients, the other haplotype (not harboring the E1506K variant) was different; specifically, none of the patients was homozygous for the E1506K allele and the surrounding haplotype. If the phenotype was caused by a recessive mechanism, one would expect to see at least some conservation of the haplotypes among the patients, because the patients all come from a small subpopulation and indeed from different branches of a large pedigree. If the inheritance were recessive, the fact that six different haplotypes were observed among the non-E1506K chromosomes would imply that at least six different mutations segregated within this subpopulation, which is unlikely considering the overall rarity of the disease. Furthermore, if one considers the assumption of multiple mutations reasonable, then each of the six mutations must involve noncoding parts of the gene, because no additional coding variants were detected among the patients' SUR1 alleles. Both coincidences must be so rare that a dominant inheritance of the E1506K allele remains the most likely explanation. There is ample evidence for different mutations within a single gene producing both dominant and recessive disease; the classical example is $\beta$-globin and different hemoglobinopathies, some of them dominant, some recessive, depending on the point mutation (31).

Interestingly, all but one of the mothers of E1506K patients had impaired glucose tolerance during pregnancy, including those two who had suffered from hypoglycemia in infancy. Two of them have developed diabetes. Furthermore, the grandmother of cases 1, 4, and 5 has diabetes. The severely blunted first-phase glucose-stimulated insulin secretion reduced maximal glucose-stimulated insulin secretory capacity, and largely normal insulin sensitivity indicated that the mothers of cases 1 and 4 predominantly had the insulin secretion-deficient phenotype of type 2 diabetes.

These observations suggest that after hypoglycemia early in life, the mutation predisposes to the development of insulin deficiency and diabetes. The development of diabetes later in life has also been reported in the dominant form of CHI caused by a gain-of-function glucokinase mutation (8). This is also in agreement with a transgenic animal model of CHI expressing a dominant-negative form of the $\mathrm{K}_{\mathrm{ATP}}$ channel subunit Kir6.2 (32). In these mice, hyperinsulinism is evident in the neonatal period but insulin-deficient diabetes develops later, apparently owing to a high frequency of $\beta$-cell apoptosis that results in decreased $\beta$ cell mass. An increased rate of $\beta$-cell apoptosis has also been found in the focal form of CHI (33). Increased $\beta$ cell apoptosis is thus a possible explanation for the development of diabetes in our patients.

$\mathrm{CHI}$ is associated with $\beta$-cell depolarization, increased $\mathrm{Ca}^{2+}$ entry, and elevated intracellular $\mathrm{Ca}^{2+}$. It is possible that the enhanced energy demand associated with $\mathrm{Ca}^{2+}$ extrusion from the $\beta$ cell, coupled with an elevated $\left[\mathrm{Ca}^{2+}\right]_{\text {i }}$, is responsible for precipitating $\beta$-cell apoptosis. If this is the case, diazoxide therapy, by hyperpolarizing the $\beta$ cell and limiting $\mathrm{Ca}^{2+}$ entry, might delay the onset of apoptosis and progression to diabetes.

All patients carrying the E1506K mutation who were treated with diazoxide responded well. The two mildest cases (2 and 3 ) needed only a few weeks of intravenous glucose administration and frequent 
feedings subsequently. One patient (case 1) was treated surgically at the age of 3.5 years. It is possible that this patient, who has since developed diabetes, could have been managed effectively by diazoxide treatment without pancreatectomy.

It is noteworthy that in all six core families, the patients inherited the E1506K allele from their mother $(P=0.0156)$. This parental skewing could be due to chance, but is also compatible with imprinting, i.e., a functional difference between the maternal and paternal alleles. In this context, it might be of interest to measure the level of SUR1 transcription from maternal and paternal alleles in islet cells.

Previous studies of the focal form of $\mathrm{CHI}$ have revealed a loss of maternal alleles resulting in a reduction to homozygosity of paternal SUR1 mutations within the focal lesion (12). To investigate the possibility that a similar mechanism existed in our patients, the resected pancreas of patient 1 was studied (no other patients underwent resection). Although we sought for the loss of heterozygosity in DNA from the resected pancreatic tissue, no loss of alleles was detected. Furthermore, the absence of atrophic resting islets and the observation of large $\beta$ cells with abnormally large nuclei in different parts of the gland constitute strong arguments in favor of a diffuse form of the disease (34). The volume density of the endocrine cells and their relative proportions are similar in this case to those usually observed in this age group, both in normoglycemic and hypoglycemic infants and children with the diffuse form of CHI (20). The mean $\beta$ cell nuclear radius and $\beta$-cell nuclear crowding, respectively, $4.61 \mu \mathrm{m}$ and 9.94 nuclei per $1,000 \mu \mathrm{m}^{2}$, are characteristic of the diffuse form of the disease and thus allow the exclusion of a focal lesion (21).

The results of the electrophysiological analysis of $\mathrm{K}_{\mathrm{ATP}}$ channels containing the CHI mutation SUR1-E1506K are able to account fully for the observed clinical phenotype. The SUR1-E1506K mutation leads to a reduction, but not a complete loss, of $\mathrm{K}_{\mathrm{ATP}}$ channels. Consistent with the clinical phenotype, the mutant channels are insensitive to metabolic inhibition but are activated by diazoxide. Our results demonstrate that MgADP is unable to stimulate mutant channel activity. This effect has been reported for other $\mathrm{CHI}$ mutations and may partially underlie the inability of metabolic inhibition to stimulate $\mathrm{K}_{\text {ATP }}$ channel activity (35). The E1506K mutation lies within the second nucleotide-binding domain (NBD) of SUR1 just distal to the Walker B motif. In other $A B C$ transporters, this motif is involved in binding the $\mathrm{Mg}^{2+}$ ion of Mg-nucleotides (36). Mutation of the adjacent aspartate residue (D1505) also abolishes the stimulatory effects of Mg-nucleotides (MgADP, MgATP) and prevents $\mathrm{K}_{\mathrm{ATP}}$ channel activation by metabolic inhibition in intact cells $(25,35)$. It therefore seems plausible that the E1506K CHI mutation abolishes metabolic activation by decreasing $\mathrm{Mg}^{2+}$ binding to the Walker motif of SUR1, and thereby impairing Mg-nucleotide interactions.
It is well established that diazoxide activation of $\beta$-cell $\mathrm{K}_{\mathrm{ATP}}$ channels requires the presence of $\mathrm{Mg}$-nucleotide (MgATP or MgADP) at the intracellular membrane surface $(37,38)$. Thus, it is not surprising that mutations of NBD1 or NBD2 that abolish the potentiatory effect of MgADP may impair diazoxide activation $(25,39)$. It is therefore interesting that diazoxide was able to activate Kir6.2/SUR1-E1506K channels, despite the loss of MgADP stimulation. A similar finding has been observed for another CHI mutation (14769R in NBF2) (25) and for a recombinant mutation in the Walker A motif of NBD2 of SUR1 (K11384M) (25). This phenomenon underlies the ability of diazoxide to reduce insulin secretion in patients carrying this mutation.

Our results suggest that the SUR1-E1506K does not exert a dominant negative effect on wild-type SUR1. Instead, the amount of current produced when SUR1 and SUR1-E1506K are expressed in the same oocyte is consistent with the concentration of SUR1 mRNA injected. Our results do not enable us to determine whether or not heteromeric channels containing both wild-type and mutant SUR subunits exist; however, if heteromeric channels are viable, our data suggest the extent to which they are activated by metabolic inhibition is proportional to the number of SUR1 subunits they contain.

All CHI mutations reported to date are inherited in a recessive fashion, which suggests that a $50 \%$ reduction in the $\beta$-cell $\mathrm{K}_{\mathrm{ATP}}$ current is not sufficient to produce a membrane depolarization large enough to cause unregulated insulin secretion. It is therefore somewhat surprising that the $\mathrm{E} 1506 \mathrm{~K}$ mutation, which produces a $50 \%$ reduction in current amplitude when coexpressed with wild-type SUR1 in a 1:1 ratio, shows dominant inheritance. Although it is possible that the level of expression of mutant SURs may differ when heterologously expressed in Xenopus oocytes and in mammalian cells, it does not seem likely that the E1506K mutation would have a dominant negative effect in $\beta$ cells when it does not in Xenopus oocytes. The reason for the dominant inheritance of the E1506K mutation remains unclear. It is possible, however, that it arises from genetic imprinting, which results in poor expression of the paternally inherited wild-type SUR1 allele.

The consequences of the mutation $\mathrm{E} 1506 \mathrm{~K}$ and the previously reported Finnish founder mutation V187D differ both in vivo and in vitro. The mutation V187D causes a drug-resistant form of $\mathrm{CHI}$ that necessitates pancreatectomy, whereas the E1506K-associated form of $\mathrm{CHI}$ responds well to medical treatment with diazoxide. Together, these two mutations explain the genetic basis of about 58\% (22/38) Finnish CHI cases. Differentiation of these two forms of the disease is of great importance in clinical decision making. In the case of the mutation E1506K, diazoxide therapy should be the treatment of choice, whereas the patients carrying the V187D mutation will need surgical treatment.

In conclusion, we have found a pedigree in which a dominantly inherited SUR1 mutation causes a diazoxide-responsive form of CHI. This mutation predisposes 
to the later development of insulin deficiency and diabetes, demonstrating that mild genetic defects in the $\beta$ cell $\mathrm{K}_{\mathrm{ATP}}$ channels can be a cause of adult-onset diabetes.

\section{Acknowledgments}

We thank P. Kärkkäinen, R. Laitinen, E. Ruotsalainen, and L. Uschanoff for skilled technical assistance; V. Ollikainen for expert help with linkage analysis; and B. Glaser for help with SUR1 promoter sequence analysis. These studies were supported by the Foundation for Paediatric Research (H. Huopio and T. Otonkoski), Yamanouchi Research International, the Wellcome Trust, and the British Diabetic Association (F. Ashcroft). J. Kere is an Investigator of the Center of Excellence for Disease Genetics of the Academy of Finland. T. Otonkoski was the recipient of a Juvenile Diabetes Foundation International Career Development Award. J. Rahier was supported by grant J.4594.99 from the FRSM, Brussels, Belgium.

1. Aynsley-Green, A. 1981. Nesidioblastosis of the pancreas in infancy. Dev. Med. Child Neurol. 23:372-379.

2. Permutt, M.A., Nestorowicz, A., and Glaser, B. 1996. Familial hyperinsulinism: an inherited disorder of spontaneous hypoglycemia in neonates and infants. Diabetes Rev. 4:347-355.

3. Meissner, T., Brune, W., and Mayatepek, E. 1997. Persistent hyperinsulinaemic hypoglycaemia of infancy: therapy, clinical outcome and mutational analysis. Eur. J. Pediatr. 156:754-757.

4. Aynsley-Green, A., et al. 2000. Practical management of hyperinsulinism in infancy. Arch. Dis. Child. 82:F98-F107.

5. Thomas, P.M., et al. 1995. Mutations in the sulfonylurea receptor gene in familial persistent hyperinsulinemic hypoglycemia of infancy. Science. 268:426-429.

6. Thomas, P., Ye, Y., and Lightner, E. 1996. Mutation of the pancreatic islet inward rectifier Kir6.2 also leads to familial persistent hyperinsulinemic hypoglycemia of infancy. Hum. Mol. Genet. 5:1809-1812.

7. Nestorowicz, A., et al. 1997. A nonsense mutation in the inward rectifier potassium channel gene, Kir6.2, is associated with familial hyperinsulinism. Diabetes. 46:1743-1748.

8. Glaser, B., et al. 1998. Familial hyperinsulinism caused by an activating glucokinase mutation. N. Engl. J. Med. 338:226-230.

9. Stanley, C.A., et al. 1998. Hyperinsulinism and hyperammonemia in infants with regulatory mutations of the glutamate dehydrogenase gene. N. Engl. J. Med. 338:1352-1357.

10. Glaser, B., Thornton, P., Otonkoski, T., and Junien, C. 2000. Genetics of neonatal hyperinsulinism. Arch. Dis. Child. 82:F79-F86.

11. Aguilar-Bryan, L., and Bryan, J. 1999. Molecular biology of adenosine triphosphate-sensitive potassium channels. Endocr. Rev. 20:101-135.

12. De Lonlay, P., et al. 1997. Somatic deletion of the imprinted 11p15 region in sporadic persistent hyperinsulinemic hypoglycemia of infan$\mathrm{cy}$ is specific of focal adenomatous hyperplasia and endorses partial pancreatectomy. J. Clin. Invest. 100:802-807.

13. Otonkoski, T., et al. 1999. A point mutation inactivating the sulfonylurea receptor causes the severe form of persistent hyperinsulinemic hypoglycemia of infancy in Finland. Diabetes. 48:408-415.

14. Bruining, G.J. 1990. Recent advances in hyperinsulinism and pathogenesis of diabetes mellitus. Curr. Opin. Pediatr. 2:758-765.

15. Inoue, H., et al. 1997. Sequence variants in the pancreatic islet beta-cell inwardly rectifying $\mathrm{K}+$ channel Kir6.2 (Bir) gene: identification and lack of role in Caucasian patients with NIDDM. Diabetes. 46:502-507.
16. Nestorowicz, A., et al. 1996. Mutations in the sulonylurea receptor gene are associated with familial hyperinsulinism in Ashkenazi Jews. Hum. Mol. Genet. 5:1813-1822.

17. Lehto, M., et al. 1999. High frequency of mutations in MODY and mitochondrial genes in Scandinavian patients with familial early-onset diabetes. Diabetologia. 42:1131-1137.

18. Orita, M., Iwahana, H., Kanazawa, H., Hayashi, K., and Sekiya, T. 1989. Detection of polymorphisms of human DNA by gel electrophoresis as single-strand conformation polymorphisms. Proc. Natl. Acad. Sci. USA. 86:2766-2770.

19. Lathrop, G.M., Lalouel, J.M., Julier, C., and Ott, J. 1984. Strategies for multilocus linkage analysis in humans. Proc. Natl. Acad. Sci. USA. 81:3443-3446.

20. Rahier, J., et al. 1984. The basic structural lesion of persistent neonatal hypoglycaemia with hyperinsulinism: deficiency of pancreatic D cells or hyperactivity of B cells? Diabetologia. 26:282-289.

21. Sempoux, C., et al. 1998. Neonatal hyperinsulinemic hypoglycemia: heterogeneity of the syndrome and keys for differential diagnosis. J. Clin. Endocrinol. Metab. 83:1455-1461.

22. DeFronzo, R.A., Tobin, J.D., and Andres, R. 1979. Glucose clamp technique: a method for quantifying insulin secretion and resistance. Am.J. Physiol. 237:E214-E223.

23. Inagaki, N., et al. 1995. Reconstitution of IKATP: an inward rectifier subunit plus the sulfonylurea receptor. Science. 270:1166-1170.

24. Sakura, H., Ammala, C., Smith, P.A., Gribble, F.M., and Ashcroft, F.M. 1995. Cloning and functional expression of the cDNA encoding a novel ATP-sensitive potassium channel subunit expressed in pancreatic betacells, brain, heart and skeletal muscle. FEBS Lett. 377:338-344.

25. Gribble, F.M., Tucker, S.J., and Ashcroft, F.M. 1997. The essential role of the Walker A motifs of SUR1 in K-ATP channel activation by MgADP and diazoxide. $E M B O J$. 16:1145-1152.

26. 1985. Diabetes mellitus. World Health Organization. Technical Report Series, No. 727. Geneva, Switzerland. 10-11.

27. Gribble, F.M., Tucker, S.J., Seino, S., and Ashcroft, F.M. 1998. Tissue specificity of sulphonylureas: studies on cloned cardiac and beta-cell KKATP channels. Diabetes. 47:1412-1418.

28. Koster, J.C., Sha, Q., Shyng, S.L., and Nichols, C.G. 1999. ATP inhibition of KATP channels: control of nucleotide sensitivity by N-terminal domain of the Kir6.2 subunit. J. Physiol. 515:19-30.

29. Ashcroft, F.M., and Rorsman, P. 1989. Electrophysiology of the pancreatic beta-cell. Prog. Biophys. Mol. Biol. 54:87-143.

30. Ashcroft, F.M., and Ashcroft, S.J. 1990. Properties and functions of ATPsensitive K-channels. Cell. Signal. 2:197-214.

31. Hemoglobin--beta locus; HBB. http://www.ncbi.nlm.nih.gov/Omim/. Entry no. 141900.

32. Miki, T., et al. 1997. Abnormalities of pancreatic islets by targeted expression of a dominant-negative KATP channel. Proc. Natl. Acad. Sci. USA. 94:11969-11973.

33. Glaser, B., et al. 1999. Hyperinsulinism caused by paternal-specific inheritance of a recessive mutation in the sulfonylurea-receptor gene. Diabetes. 48:1652-1657.

34. Rahier, J., et al. 1998. Partial or near-total pancreatectomy for persistent neonatal hyperinsulinaemic hypoglycaemia: the pathologist's role. Histopathology. 32:15-19.

35. Nichols, C.G., et al. 1996. Adenosine diphosphate as an intracellular regulator of insulin secretion. Science. 272:1785-1787.

36. Higgins, C. 1992. ABC transporters: from microorganism to man. Annu. Rev. Cell. Biol. 8:67-113.

37. Kozlowski, R.J., Hales, C.N., and Ashford, M.L.J. 1989. Dual effects of diazoxide on ATP-K+ currents recorded from insulin secreting cell line. Br. J. Pharmacol. 97:1039-1050.

38. Edwards, G., and Weston, A.H. 1993. The pharmacology of ATP-sensitive potassium channels. Annu. Rev. Pharmacol. Toxicol. 33:597-637.

39. Shyng, S.L., Ferrigni, T., and Nichols, C.G. 1999. Regulation of KATP channel activity by diazoxide and MgADP. J. Gen. Physiol. 110:643-654.

40. Vauhkonen, I., et al. 2000. Impaired insulin secretion in non-diabetic offspring of probands with latent autoimmune diabetes mellitus in adults. Diabetologia. 43:69-78. 